\title{
Aerospace Vehicle Systems Engineering and the Importance of Meteorology Inputs in Design
}

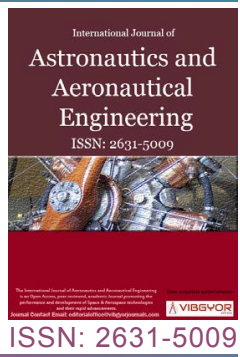

\section{William W Vaughan ${ }^{{ }^{*}}$ and Dale L Johnson ${ }^{2}$}

${ }^{1}$ NASA Emeritus, Huntsville, USA

${ }^{2}$ NASA Retired, Madison, USA

\begin{abstract}
Aerospace Meteorology plays an important role in the design, development, and operation of aerospace vehicles. Many of the System Engineering issues and lessons presented herein occurred during the involvement of the authors with the development and interpretation of aerospace natural environment inputs, especially those of the terrestrial environment $(0-90 \mathrm{~km}$ altitude). Background for the actions needed to avoid the issue being repeated or the lesson having to be re-learned is addressed. The engineering application importance and some issues associated with the presentation and interpretation of terrestrial environment guidelines associated with aerospace meteorology elements are presented.

This chapter addresses the philosophy regarding the application of the natural environment relative to the engineering design and development of aerospace vehicles. This includes some of the key Aerospace Meteorology issues and "lessons learned" that have been identified over a number of years and documented from the development and application of terrestrial environment design criteria. Background regarding basis for the lesson and a description of the specific lesson is provided. References 1,2 and 3 contributed to the formation of this chapter [1-3].
\end{abstract}

\section{Keywords}

Aerospace meteorology, Aerospace vehicle design, Lessons learned, Terrestrial and space environment, Systems engineering

\section{Introduction}

The natural environment is a significant input and consideration in the design and operation of aerospace vehicles and in the integrity of associated systems and elements. An aerospace vehicle is typically defined as a vehicle capable of flight within and outside the sensible atmosphere. A launch vehicle is a rocket or other vehicle used to launch a spacecraft, satellite, etc. and is an element of an aerospace vehicle. A spacecraft is a device, manned and unmanned, which is designed to be placed into an orbit about the earth or into a trajectory to another celestial body. The term aerospace vehicle is usually used to reflect the launch vehicle and spacecraft. A comprehensive set of design, development, and operational guidelines for aerospace vehicles arises from actual engineering

*Corresponding author: William W Vaughan, NASA Emeritus, Huntsville, AL, USA

Accepted: April 09, 2019; Published: April 11, 2019

Copyright: (c) 2019 Vaughan WW, et al. This is an open-access article distributed under the terms of the Creative Commons Attribution License, which permits unrestricted use, distribution, and reproduction in any medium, provided the original author and source are credited.

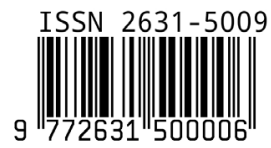

Vaughan and Johnson. Int J Astronaut Aeronautical Eng 2019, 4:028 
problems and mission needs encountered in operations within the Earth's atmosphere.

The natural environment consists of both the terrestrial environment $(0-90 \mathrm{~km}$ altitude) and the space environment (>90 km altitude). This chapter is based on the contents of the 2008 report by Johnson [1]. The terrestrial environment design criteria guidelines given in this reference are based on the interpretation of statistics and models of atmospheric, climatic, and other terrestrial phenomena relative to various aerospace vehicle design, development, and operational requirements. Aerospace vehicle terrestrial environment design guidelines are provided for 13 atmospheric and/or geo-physical parameters as mentioned in the Introduction to this book.

Most all of the natural environment criteria guidelines presented in the NASA report [1] were formulated based on mission requirements and discussions with, and requests from, engineers involved in aerospace vehicle development, operations, and mission planning. Therefore, they represent responses regarding the terrestrial environment to actual engineering problems and mission requirements, and are not just a general compilation of environmental data. NASA Centers, various other Government agencies, and their associated contractors responsible for the design, systems engineering, mission planning, and operational studies associated with aerospace vehicle development have used this report [1] extensively as a source for guidelines relative to the formulation of terrestrial environment design requirements and criteria. The first version of the report was published in 1961 [4] and has subsequently been updated periodically since that time by the NASA Marshall Space Flight Center (MSFC). This Chapter presents a variety of lessons learned regarding terrestrial environment interpretation and application as reflected in Johnson [1]. They illustrate how the various natural environment parameters impact and help address engineering design and development problems dealing with the natural environment. Both the atmosphere and the oceanic influences can impact aerospace vehicle launch or landing, and oceanic recovery.

Another important document related to the scope of this Chapter is by Vaughan [5] (i.e., "Guide to Reference and Standard Atmosphere Models" published as AIAA-G-003C-2010). This document contains descriptions of over 75 Earth and planetary reference and standard atmosphere models developed by national and international organizations. It provides information on the models regarding the scope, data bases, uncertainties, sources for codes, and applicable references. It was prepared based on the contributions of numerous authors. The objective of the Guide is to enable the reader to more readily ascertain the applicability of a model for their intended use.

The Space Shuttle and the Saturn-Apollo Vehicle represent two of the major NASA aerospace vehicle development and operational accomplishments of the United States. Aerospace meteorology played a key role relative to the definition of the design, development, systems engineering, and operational requirements for the development and operational support of these vehicles. Weather support for operations is a key element of aerospace meteorology and provides a very important contribution relative to enabling aerospace vehicles to perform their missions with minimum risk. The weather support provided to the Space Shuttle as an element of aerospace meteorology is addressed in the paper by Bellue, et al. [6].

\section{Systems Engineering Discussion}

Systems Engineering is fundamental to good engineering, which in turn depends on the integration and application of engineering lessons learned and technical standards [7]. Thus, good Systems Engineering also depends on systems engineering lessons learned from within the aerospace industry being documented and applied. About ten percent of the engineering lessons learned documented in the NASA Lessons Learned Information System are directly related to Systems Engineering. A key issue associated with lessons learned datasets is the communication and incorporation of this information into engineering processes.

Systems Engineering has been defined (EIA/IS632) as "an interdisciplinary approach encompassing the entire technical effort to evolve and verify an integrated and life-cycle balanced set of system people, product, and process solutions that satisfy customer needs". Wikipedia defines it as: Systems engineering is an interdisciplinary field of engineering and engineering management that focuses on how to design and manage complex systems over their life cycles. At its core, systems engineering 
utilizes systems thinking principles to organize this body of knowledge.

The European Cooperation for Space Standardization (ECSS), a component of the European Space Agency [8], defines systems engineering similarly as "an interdisciplinary approach governing the total technical effort to transform requirements into a system solution". These requirements include hardware, software, firmware, human resources, information, techniques, facilities, services, and other support elements such as the aerospace environment. Technical excellence is the key to successful systems engineering and, thus, a successful project [8]. The systems engineering process is intrinsically iterative across the whole life cycle of the project and is produced under the leadership of engineering talents with technical excellence attributes. Systems engineering is not an administrative focused or led function. Technical excellence is the key to successful systems engineering and, thus, to a successful project. The aerospace environment is a fundamental element of the interdisciplinary approach of systems engineering.

Designing reliable space-based systems has always been a goal for NASA, and many painful lessons have been learned along the way. One of the continuing functions of a systems engineer is to compile development and operations "lessons learned" documents and ensure their integration into future systems development activities. They can produce insights and information for risk identification on a new project. Lessons learned files from previous projects are especially valuable in risk identification and characterization.

Within the life cycle process, a number of essential functional systems engineering processes are necessary to provide customer satisfaction. One of the key processes is training. Fundamental to any training is the exploitation of lessons learned files, thus enabling the achievement and maintenance of skills and abilities necessary to perform the necessary processes throughout the life cycle for an aerospace vehicle development and its flight in the terrestrial and space environments.

As part of the NASA Technical Standards Program activities, engineering lessons learned datasets have been identified from a number of sources. These are then searched and screened for those having a relation to Technical Standards. This paper will address some of the Systems Engineering Lessons Learned with respect to how they are being related to Technical Standards within the NASA Technical Standards Program. They are also being linked to the Agency's Interactive Engineering Discipline Training Courses with respect to the life cycle for an aerospace vehicle development and its flight within the terrestrial and space environments.

An article [9] that addressed new synergies between systems engineering and diminishment of manufacturing sources and material shortages made two important points:

(a) Systems engineering principles and best practices should be applied to enhance reliability, availability, maintainability, and sustainability through the entire life of a program.

(b) Managing major programs effectively requires sound systems engineering.

Accordingly, [10], presents technical excellence and the associated "tall poles" - i.e,

(a) Pay attention to details;

(b) Leave no stone unturned; and

(c) Be aggressive - not passive

are all integral to ensure the applications of the principals and best practices of systems engineering to aerospace programs, as well as to other programs, achieving the intended goals $[11,12]$.

\section{Aerospace Meteorology Historical Discussion}

A historical note [2] regarding the origin and development of the term aerospace meteorology by the coauthor William W. Vaughan is presented. It is based on recollections and a preliminary search of some past issues of the Bulletin of the American Meteorological Society.

In March 1964 the American Meteorological Society (AMS)'s Bulletin made reference to a proposed statement on meteorology and aerospace vehicles prepared by the AMS Committee on Atmospheric Problems of Aerospace Vehicles and the American Institute of Aeronautics and Astronautics (AIAA) Atmospheric Environment Technical Committee. The statement was published in the June 1964 issue of the Bulletin.

From 2 to 6 March 1964, the AMS's Fifth Conference on Applied Meteorology: Atmospheric 
Problems of Aerospace Vehicles was held in Atlantic City, New Jersey. Prior to this time, conferences on applied meteorology included wordage associated with upper atmosphere and satellite exploration, meteorological rocketry, support of aerospace testing and operations, and atmospheric problems of aerospace vehicles.

It seems the first conference to use the words aerospace meteorology was entitled Sixth National Conference on Applied Meteorology (aerospace meteorology), cosponsored with the AIAA Atmospheric Environment Technical Committee and held on 28-31 March 1966 in Los Angeles, California. Just who in NASA "coined" the term aerospace meteorology I am not sure. The term aerospace meteorology encompassed both meteorological support activities at the various test ranges and within the organizations developing meteorological requirements for the design and development of aerospace vehicles.

Somewhere along the way, there was an attempt within AMS to distinguish between the two support activities as aerospace meteorology and range meteorology (rather like distinguishing between aviation meteorology activities as being aviation meteorology and airport meteorology). This subsequently led to the usage by AMS of the term ARAM to represent aviation, range, and aerospace meteorology activities.

The Bulletin contains an announcement about the Seventh Conference on Aviation, Range, and Aerospace Meteorology, held on 2-7 February 1997 in Long Beach, California. It evidently took the conference number from the previous numbering of the aviation weather system conferences.

The AMS Aviation, Range, and Aerospace Meteorology Technical Committee, often in collaboration with the AIAA Atmospheric and Space Environment Technical Committee, subsequently cosponsored many of AMS's aviation, range, and aerospace meteorology conferences.

\section{Engineering Importance}

It is important to recognize the need to define the terrestrial environment requirements very early in the design and development cycle of any aerospace vehicle [13]. The attached Bibliography provides a number of documents that address this and related subjects in this chapter. Using the desired operational capabilities, launch locations, and flight profiles for the aerospace vehicle, specific definitions of the terrestrial environment can be provided which, if the aerospace vehicle is designed to accommodate, will ensure the desired operational capability within the defined design risk level. It is very important that those responsible for the terrestrial and space environment definitions and requirements for the design and development of an aerospace vehicle have a close working relationship with program management and design engineers. This will then ensure that the desired operational capabilities are reflected in the terrestrial and space environment requirements specified for design and development of the vehicle and, accordingly, their interpretation relative to engineering applications.

An aerospace vehicle's response to terrestrial and space environment design criteria must be carefully evaluated to ensure an acceptable design relative to desired operational requirements. The choice of criteria depends on the specific launch and landing location(s), vehicle configuration, and expected mission(s). Vehicle design, operation, and flight procedures can be separated into particular categories for proper assessment of environmental influences and impact on the life history of each vehicle and all associated systems. These include categories such as (1) Purpose and concept of the vehicle, (2) Preliminary engineering design, (3) Structural design, (4) Control system design, (5) Flight mechanics, orbital mechanics, and performance (trajectory shaping), (6) Optimization of design limits regarding the various natural environmental factors, and (7) Final assessment of the terrestrial environmental capability for launch and flight operations.

One must remember that the flight profile of all aerospace vehicles includes the terrestrial environment. Thus, an aerospace vehicle's operations will always be influenced to some degree by the terrestrial environment with which it interacts. As a result, the definition of the terrestrial environment and its interpretation is one of the significant aerospace vehicle design and development inputs. This definition plays key roles; for example, in the areas of structures, control systems, trajectory shaping (performance), aerodynamic heating, and takeoff/ landing capabilities. The aerospace vehicle's capabilities that result from the design, in turn, determine the constraints and flight opportunities for 


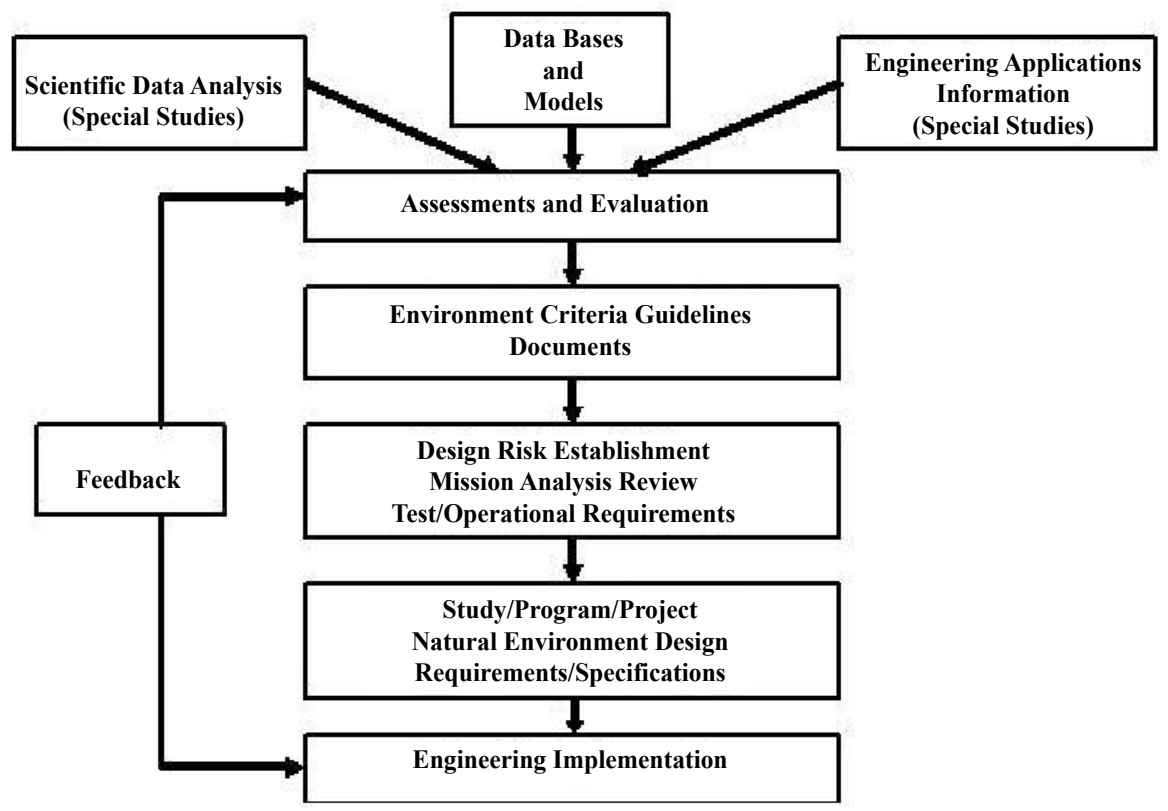

Figure 1: Natural terrestrial environment definition and analysis for aerospace vehicle engineering application.

tests and operations.

The close association between the design and test engineering groups and those responsible (central control point) for the terrestrial and space environment inputs is important to the success of the vehicle's development process. This procedure has been followed in many NASA aerospace vehicle developments and is of particular importance for any new aerospace vehicle. Figure 1 illustrates the necessary interactions relative to terrestrial and space environment definition and engineering application. Feedback is critical to the aerospace vehicle development process relative to terrestrial and space environment requirements and their interpretation, and thus to the ability to produce a viable aerospace vehicle design and operational capability.

\section{Some Terrestrial Environment Issues}

For extremes in the terrestrial environments, there generally is no known physical upper or lower bound. However, wind speed does have a strict physical lower bound of zero. Essentially all observed extreme conditions have a finite probability of being exceeded. Consequently, terrestrial environment extremes used for the development of design requirements must be accepted with the knowledge that there is some risk of the values being exceeded. The measurement of many environmental parameters is not as accurate as desired. In some cases, theoretical model estimates are believed to be more useful for design use than those indicated by empirical measured distributions from short periods of record. Therefore, theoretical values can be given considerable weight in selecting the extreme values for some parameters; for example, peak surface winds. Criteria guidelines are presented for various percentiles based on the available data. Caution should be exercised in the interpretation of these percentiles in aerospace vehicle studies to ensure consistency with physical reality and the specific design and operational problems of concern.

Aerospace vehicles are not normally designed for launch and flight in severe weather conditions such as hurricanes, thunderstorms, ice storms, and squalls. Environmental parameters associated with severe weather that may be hazardous to aerospace vehicles and associated ground support equipment include strong ground and in-flight winds, strong upper level wind shears and gusts, turbulence, icing conditions, and electrical activity. The terrestrial environment guidelines report [1] noted in this chapter provides information relative to those severe weather characteristics that should be included in aerospace vehicle flight, on-pad, and associated in facilities design requirements and specifications, when required to meet the aerospace vehicle program's mission operational requirements. For example, the Saturn and Shuttle vehicles were designed for the "worse wind month" at the 95\% winds (with 99\% shear 
and gust) launch capability level for structural and control requirements at Max $Q$ (dynamic pressure), thereby producing higher launch capability levels for other months - thus a maximum of $5 \%$ launch delay risk for "worst wind month" and less for other months relative to in-flight winds. This philosophy also provides some flexibility to accommodate engineering design and development issues that may arise. Given that one has pre-launch wind monitoring and flight simulation inputs for use in making the final decision to launch, there is essentially zero chance of compromising a vehicle because of design-level ascent wind loads or control capability being exceeded.

Although an aerospace vehicle design ideally should accommodate all expected operational natural environment (terrestrial and space) conditions, it is neither economically nor technically feasible to design an aerospace vehicle to withstand all natural environment extremes. For this reason, consideration should be given to protecting an aerospace vehicle from some extremes. This can be achieved by using support equipment and specialized forecast personnel to advise on the expected occurrence, for example, of critical terrestrial environment conditions - so necessary actions can be taken accordingly. The services of specialized forecast personnel may be very economical compared to the more expensive vehicle designs that would be required to cope with all terrestrial environment possibilities.

Table 1 provides an excellent reference guide for the aerospace terrestrial environment specialist, program managers, design engineers, and others on the development team for a new aerospace vehicle program. It provides an excellent overview of the elements and scope of aerospace meteorology relative to influences on an aerospace vehicle. This information summarizes potential terrestrial environment areas of engineering concern when first surveying the design requirements for a new aerospace vehicle project. As the table indicates, terrestrial environment phenomena may significantly affect multiple areas of an aerospace vehicle's design, and thus operational capabilities, including areas involving structure, control, trajectory shaping (performance), heating, takeoff, in-flight, and landing capabilities, materials, among others.

Some Other Terrestrial Environment Con-

\section{siderations}

Experience gained and lessons learned from developing terrestrial environment design criteria for previous aerospace vehicle programs have proven that, in order to be most effective, the terrestrial environment design criteria for a new vehicle should:

(1) Be developed once the mission is defined, in order to ensure the desired operational performance of the aerospace vehicle.

(2) Be issued under the signature of the program manager and be part of the controlled program definition and requirement documentations.

(3) Specify terrestrial environment requirements for all phases of activity including prelaunch, launch, ascent, on-orbit, descent, and landing.

Knowledge of the terrestrial environment is also necessary to establish test requirements for aerospace vehicles and in the design of associated support equipment and facilities. Such data are required to define fabrication, storage, transportation, test, and preflight design conditions, and should be considered for both the whole vehicle system and the components which comprise the system [14].

The group with the central control point responsibility and authority to define and interpret terrestrial environment design requirements must also be in a position to pursue environment inputrelated applied research studies and engineering assessments and updates. This is necessary to ensure accurate and timely terrestrial environment inputs tailored to the program's needs. Design engineers and program managers should not assume they can simply draw on the vast statistical databases and numerous models of the terrestrial environment currently available in literature without interpretation and tailoring to specific aerospace vehicle design needs. Otherwise, this can prove to be a major deterrent to the successful development and operation of an aerospace vehicle.

Although vehicle design ideally should accommodate all expected operational environment conditions, it is neither economically nor technically feasible to design an aerospace vehicle to withstand all terrestrial environment extremes. For this reason, consideration should be given to protecting 


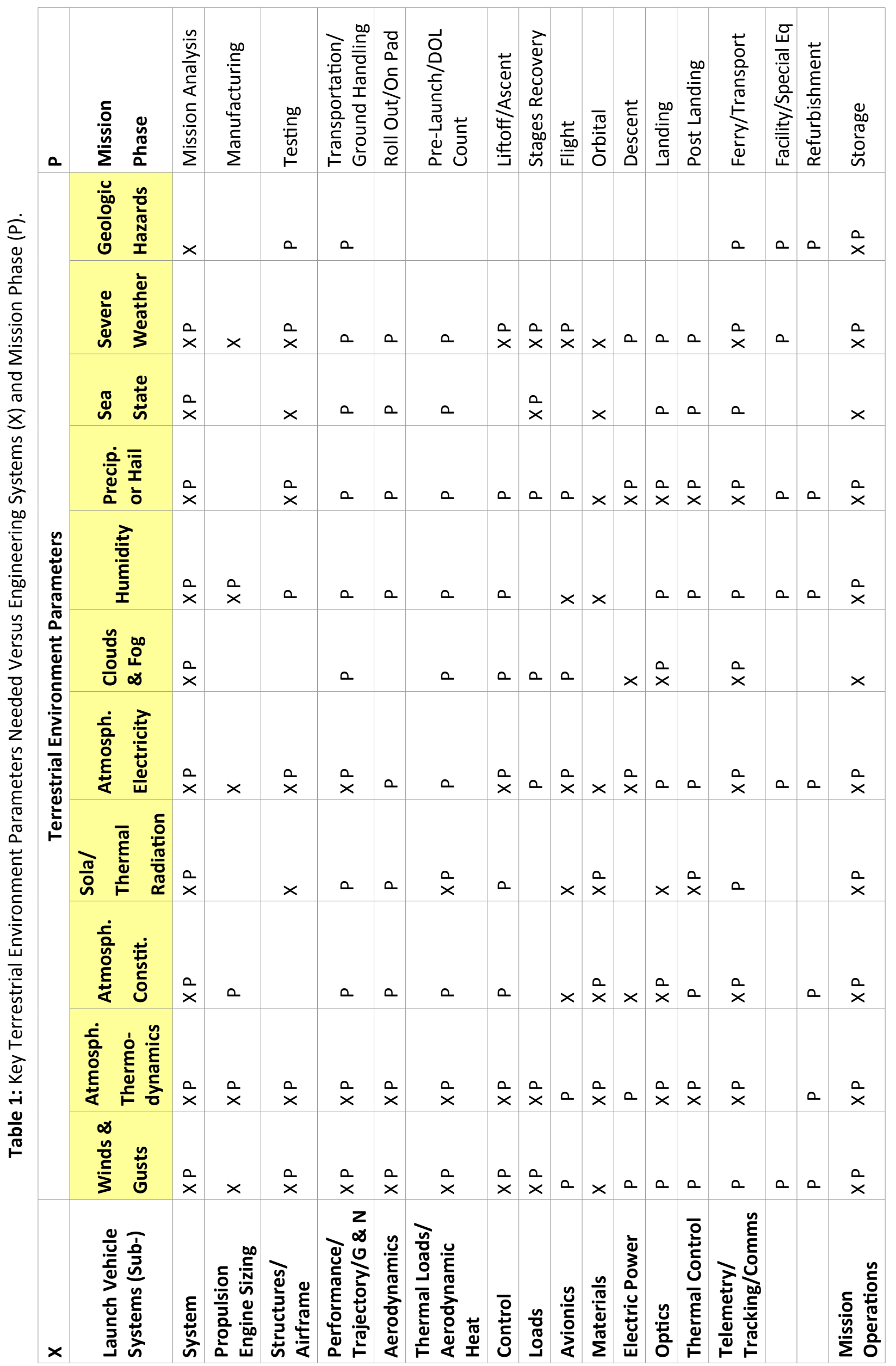


vehicles from some situations. This can be achieved by using support equipment and specialized weather forecast personnel to provide advice on the expected occurrence of critical terrestrial environment conditions. The services of specialized forecast personnel may be very economical compared to the more expensive vehicle designs that would be required to cope with all terrestrial environment possibilities.

Good systems engineering judgment must be exercised to apply terrestrial environment requirements to the aerospace vehicle's design analysis. Consideration must be given to the overall vehicle mission and system performance requirements. Knowledge is still lacking on relationships between some of the terrestrial environment parameters that are required as inputs for the design of aerospace vehicles. Also, inter-relationships between aerospace vehicle parameters and terrestrial environment variables cannot always be clearly defined. Therefore, a close working relationship and team philosophy must exist between the design, systems, and operational engineers and the respective organization's terrestrial environment central control point specialists.

In many cases, it is impossible to clearly define the limiting extreme values for a particular terrestrial environment element that may occur during the desired operational lifetime of the vehicle. However, a lower value may be defined so that the probability is small that the lower value will be exceeded during the desired operational lifetime of the vehicle. Risks of launch delay may also be acceptable versus the expense of additional design considerations. Because of these and other considerations, a value that is lower than the extreme may be a more appropriate design requirement. The terrestrial environment specialist is responsible for providing the program manager and chief engineer with pertinent information so they can determine the highest risk value that is feasible for the program. Therefore, it is very important that the aerospace vehicle program manager and the chief engineer have a good understanding of the operational risks due to the selected design terrestrial environment. Terrestrial environment elements may significantly affect multiple areas of an aerospace vehicle's design, and thus operational capabilities, including structure, control, trajectory shaping (performance), heating, takeoff and landing capabilities.
An Example of a Terrestrial Environment Area of Interest Relative to Aerospace Vehicle Design and Development

This Section presents a selected natural terrestrial environment example taken from the Terrestrial Environment (Climatic) Criteria Guidelines for Use in Aerospace Vehicle Development, 2008 Revision, NASA/TM-2008-215633 [1]. This example is intended to illustrate how to make an engineering application for many of the natural environment parameters, models, etc.

\section{Wind example: Design peak wind profile - for ground winds}

Using a Power Law relationship, as presented in TM Section 2.2.5.2 [1,15], one can determine the Peak Wind Speed Profile at any level between 0 and $150 \mathrm{~m}$ altitude, by just knowing the Peak

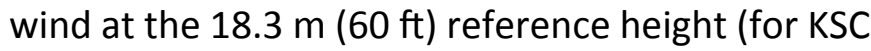
Florida):

$U(h)=U_{18.3}(h / 18.3)^{K}$

Where: $\mathrm{K}=\mathrm{C}\left(\mathrm{U}_{18.3}\right)^{-0.75}$

(and $U$ is in $\mathrm{m} / \mathrm{s}$, and $\mathrm{h}$ in $\mathrm{m}$.)

For a KSC Tower Clearance design analysis for a space vehicle launch problem example, for the windiest 1-hr exposure period, and assuming a 5\% risk, Tabular values of $C$ uses a $C=1.60$. Therefore, given a known peak wind speed of $17.7 \mathrm{~m} / \mathrm{s}$ at the $18.3 \mathrm{~m}$ level, the peak wind speed is calculated from the constructed Figure 2 to be $26.2 \mathrm{~m} / \mathrm{s}$ at $152.4 \mathrm{~m}(500 \mathrm{ft})$.

\section{Some Terrestrial Environment Related Lessons Learned}

The NASA-MSFC Natural Environments Branch and its predecessor organizations have over 50 years of experience in the development and interpretation of terrestrial environment requirements for use in the design and operation of aerospace vehicles. During this period, in addition to issues identified with the terrestrial environment inputs, a large number of "lessons learned" have formed the basis for the definition and interpretation of terrestrial environment design criteria. Three of these lessons learned are summarized below. Many other lessons learned are presented for the reader in [2,7,14-16].

Wind vectors versus engineering vector 


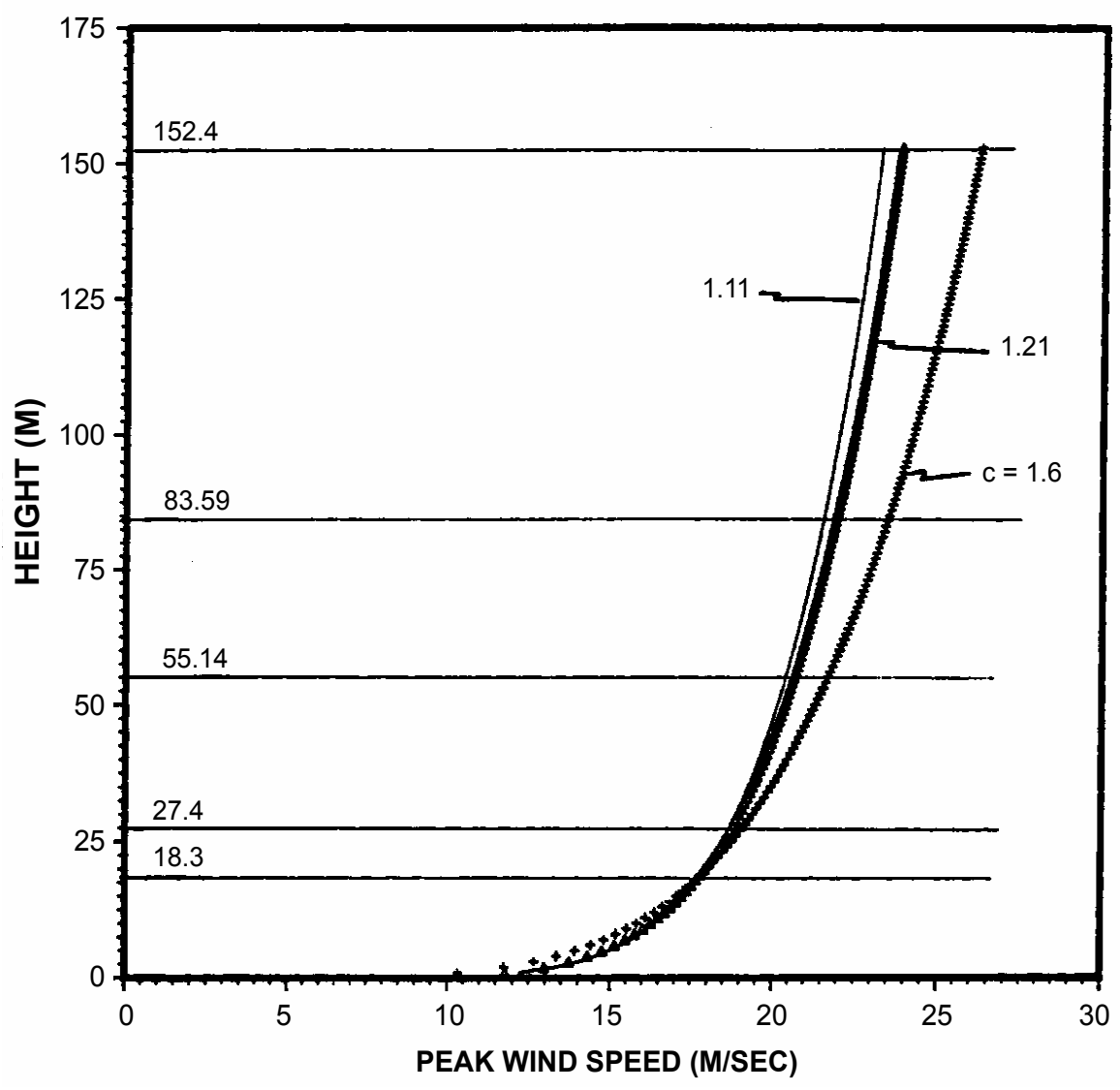

Figure 2: Ground-level peak wind speed versus height based on a power law relationship.

\section{conventions}

- Background: Flight mechanics use of wind vectors versus conventional meteorological usage created some errors by some in the calculations of structural loads and control requirements. In the case of flight mechanics, the vector is stated relative to direction that force is being applied. However, in meteorology, the wind vector is stated relative to direction from which wind force is coming.

- Lesson: The proper interpretation and application of wind vectors is important to avoid a 180응 error in structural loads and control system response calculations.

\section{Design requirements, not climatology}

- Background: While based on climatology and models, both physical and statistical, natural environment requirements are a part of the overall vehicle design effort and philosophy necessary to ensure that mission operational requirements are met. Thus, they must be selected and defined on this basis. Simply making reference to climatological databases will not produce the desired design requirements or desired robust vehicle performance.

- Lesson: Members of the natural environments group assigned as the control point for inputs to a program must also be an integral part of the vehicle design team and participate in all reviews, among others. This is necessary in order to ensure proper interpretation and application of natural environment definitions/ requirements relative to overall vehicle design requirements and thus operational capabilities to meet mission needs.

Early input of natural environment requirements based on interpretation of mission purpose and operational expectations

- Background: The natural environment definitions and requirements for a program need to be developed as soon as possible after the operational requirements for the program's mission has been defined. Thus, all concerned with the vehicle development will have a common base for natural environment inputs for use in design and mission analysis calculations. This 
will also provide an associated control for any recommended changes to natural environment definitions/requirements. Vehicle operational impacts of changes in requirements can then be readily identified.

- Lesson: The definition and control of the natural environment requirements for a vehicle design and development are necessary. This will ensure that the mission requirements are met by all concerned with the program. This will also provide visibility to all, especially the program manager and systems engineers, regarding the impact on the operation of the vehicle concerning any recommended changes in the natural environment design requirements.

\section{Conclusions}

Aerospace Meteorology plays an important role in the design, development, and operation of aerospace vehicles and in the associated integrity of aerospace systems and elements. The lessons learned examples presented relative to use of the information in Johnson [1] indicate typical ways in which the natural environment inputs can be more effectively used in aerospace vehicle design, development, and mission planning/support. It is also important that there be one common control point for all natural environment requirements and interpretation relative to an aerospace vehicle design, development, and operation requirements [17-23].

\section{References}

1. Johnson DL (2008) Terrestrial environment (Climatic) criteria guidelines for use in aerospace vehicle development - 2008 Revision. document NASA/TM2008-215633.

2. Vaughan William W, Dale L Johnson (2011) Aerospace meteorology: Some lessons learned from the development and application of NASA terrestrial environment design criteria. Bulletin of the American Meteorological Society (BAMS).

3. Vaughan William W, Dale L Johnson (2013) Aerospace meteorology: An overview of some key environmental elements. JATM 5.

4. Daniels GE (1961) Probable climatic extremes for use in msfc - space vehicle booster and associated equipment development. NASA Tech Rep MTPAERO-61-93, 56.

5. Vaughan WW (2010) AIAA Guide to reference and standard atmosphere models. American Institute of Aeronautics and Astronautics AIAA-G-003C-2010 154.

6. Bellue DG, BF Boyd, WW Vaughan, T Gamer, JW Weems, et al. (2006) 8.1 Shuttle weather support from design to launch to return to flight. $12^{\text {th }}$ Conf on Aviation, Range, and Aerospace Meteorology, Atlanta, GA, Amer Meteor Soc.

7. Gill PS, D Garcia, WW Vaughan (2005) Engineering lessons learned and systems engineering applications. $43^{\text {rd }}$ AIAA Aerospace Sciences Meeting.

8. Anon (2009) European cooperation for space standardization. System Engineering General Requirements. ECSS-E-ST-10C.

9. Bracuto C, Melnikow A, Zelinski E (2010) New synergies between systems engineering and DMSMS. Defense Standardization Program Journal 3-10.

10.Dannenberg KK (1974) Management philosophies as applied to major NASA programs. NASA-CR-141258. Washington, DC: National Aeronautics and Space Administration.

11.Gill P, Vaughan W (2008) Technical Excellence: A Requirement for Good Engineering. 47th American Institute of Aeronautics and Astronautics Aerospace Sciences Meeting.

12.Vaughan WW (2016) Systems Engineering. JATM 8: 121.

13.Johnson DL, SD Pearson, WW Vaughan, GW Batts (1997) Role of aerospace meteorology in the design, development, and operation of new advanced aerospace launch vehicles. Seventh Conference on Aviation, Range and Aerospace Meteorology, Long Beach, CA, Amer, Meteor Soc 1.2.

14.Vaughan WW, DL Johnson (2013) Aerospace meteorology: An overview of some key environmental elements. JATM 5.

15.Vaughan WW, DL Johnson (2010) Aerospace meteorology: Some lessons learned. $14^{\text {th }}$ Conference on Aviation, Range, and Aerospace Meteorology (ARAM), Atlanta, GA, Amer Meteor Soc 7.1.

16.Vaughan WW, BJ Anderson (2004) Aerospace meteorology lessons learned relative to aerospace vehicle design and operations. $11^{\text {th }}$ AMS Conference on Aviation, Range and Aerospace Meteorology, Amer Meteor Soc 6.2.

17.Allen WH (1965) Dictionary of technical terms for aerospace use. Scientific and Technical Information Division, NASA SP-7, 314.

18.Blair JC, RS Ryan, LA Schutzenhofer, WR 
Humphries (2001) Launch Vehicle Design Process: Characterization, Technical Integration and Lessons Learned. 260.

19.Johnson DL, CK Hill, WW Vaughan, SC Brown, GW Batts (1993) Natural Environment Requirements Definition and Significance for Aerospace Plane Development. $5^{\text {th }}$ International Aerospace Planes and Hypersonics Technologies Conference, Munich, Germany, American Institute of Aeronautics and Astronautics.

20.Pearson SD, WW Vaughan, GW Batts, GL Jasper (1996) Importance of the natural terrestrial environment with regard to advanced launch vehicle design and development. NASA TM 108511, 30.

21.Ryan R, J Blair, J Townsend, V Verderaime (1996) Working on the boundaries: Philosophies and practices of the design process. NASA TP-3642, 118.

22.Vaughan WW, SC Brown (1985) Natural environment considerations for space shuttle system development support. J Spacecraft and Rockets 22: 355-360.

23.Vaughan WW, DL Johnson (2010) Natural environment and aerospace vehicles: Some lessons learned. 48th American Institute of Aeronautics' Aerospace Sciences Meeting, Orlando, FL, AIAA2010-333. 